\title{
Inhibition of human glutathione transferases by pesticides: Development of a simple analytical assay for the quantification of pesticides in water
}

\author{
Evangelia G. Chronopoulou ${ }^{\mathrm{a}}$, Anastassios C. Papageorgiou ${ }^{\mathrm{b}}$, Anastassios Markoglou ${ }^{\mathrm{c}}$, Nikolaos E. Labrou $^{\mathrm{a}, *}$
}

\author{
a Laboratory of Enzyme Technology, Department of Agricultural Biotechnology, Agricultural University of Athens, Iera Odos 75, 11855 Athens, Greece \\ b Turku Centre for Biotechnology, University of Turku and Åbo Akademi University, Turku 20521, Finland \\ c Pesticide Science Laboratory, Department of Crop Science, Agricultural University of Athens, 75 Iera Odos Str., 11855 Athens, Greece
}

\section{A R T I C L E I N F O}

\section{Article history:}

Received 15 November 2011

Received in revised form 30 April 2012

Accepted 30 April 2012

Available online 9 May 2012

\section{Keywords:}

Glutathione transferase

In silico molecular docking

Pesticide determination

Xenobiotics

\begin{abstract}
A B S T R A C T
Glutathione transferases (GSTs; EC 2.5.1.18) form a group of multifunctional enzymes that are involved in phase II cellular detoxification mechanism. Here, screening of the inhibition potency of a wide range of pesticides toward selected human GST isoenzymes (hGSTA1-1, hGSTP1-1, hGSTT2-2 and hGSTO1-1) was carried out. hGSTA1-1 was found more susceptible to inhibition by pesticides than other isoenzymes. The insecticides dieldrin and spiromesifen were identified as potent reversible inhibitors toward hGSTA11 with $\mathrm{IC}_{50}$ values equal to $17.9 \pm 1.7 \mu \mathrm{M}$ and $12.1 \pm 3.4 \mu \mathrm{M}$, respectively. Based on in silico docking analysis and kinetic inhibition studies it was concluded that dieldrin and spiromesifen bind specifically to the enzyme presumably at a distinct position that partially overlaps with both the G- and H-site. The ability of dieldrin and spiromesifen to inhibit hGSTA1-1 activity was exploited for the development of analytical quantification assays for these two pesticides. Linear calibration curves were obtained for dieldrin and spiromesifen, with useful concentration in the range of $0-10 \mu \mathrm{M}$. The reproducibility of the assay response, expressed by relative standard deviation, was in the order of $4.1 \%(N=28)$. The method was successfully applied to the determination of these pesticides in real water samples without sample preparation steps.
\end{abstract}

(c) 2012 Elsevier B.V. All rights reserved.

\section{Introduction}

Glutathione transferases (GSTs, EC 2.5.1.18) comprise a family of enzymes that are involved in the detoxification mechanism of endogenous and xenobiotic electrophile compounds $[1,2]$ by catalyzing the nucleophilic attack of reduced glutathione (GSH) on the electrophilic center of these compounds.

The mammalian family of GSTs encompasses three groups of enzymes: cytosolic, mitochondrial, and microsomal. The human cytosolic GST isoenzymes constitute the largest family, which is divided in seven classes based on sequence similarity: alpha, $\mathrm{mu}$, pi, theta, zeta, omega, and sigma [2]. Cytoplasmic GSTs are active as dimers with two identical (homodimer) or two different

Abbreviations: CDNB, 1-chloro-2,4-dinitrobenzene; G-site, glutathione-binding site; GSH, glutathione; GST, glutathione transferase; H-site, hydrophobic-binding site; IPTG, isopropyl- $\beta$-D-thiogalactopyranoside; L-site, ligandin binding site; LB, Luria-Bertani; PDB, Protein Data Bank; RSD, relative standard deviation; HPLC, high performance liquid chromatography; UV-DAD, UV diode array detector.

* Corresponding author at: Enzyme Technology Laboratory, Department of Agricultural Biotechnology, Agricultural University of Athens, Iera Odos 75, 11855 Athens, Greece. Tel.: +30 210 5294308; fax: +30 2105294308 .

E-mail address: Lambrou@aua.gr (N.E. Labrou). (heterodimer) subunits [3-6]. Each subunit (22-29 kDa) contains an active site that consists of a GSH-binding site (G-site) in the Nterminal domain and a site that binds the hydrophobic substrate (H-site) in the C-terminal domain [3-6]. The H-site shows low homology between isoenzymes within each class and amongst different classes, and can bind a large variety of substrates that differ in size, structure and hydrophobicity. Accordingly, the structure of the $\mathrm{H}$-site determines substrate specificity for different xenobiotic compounds. GSTs also exhibit a ligand binding ('ligandin') function that can facilitate the binding of numerous hydrophobic and amphiphatic compounds in a nonsubstrate manner into a distinct site (this site is termed L-site). Binding of such ligands results in the inhibition of GST catalytic activity [7-11].

For the development of analytical assays based on enzyme inhibition, the measurement of the target analyte is carried out by measuring the enzyme activity before and after exposure of the enzyme at the target analyte [12-14]. Analytical assays based on enzyme inhibition can be developed using different enzymes, but so far the predominant procedures are based on the use of cholinesterases for determination of organophosphorus esters and carbamates $[14,15]$. Recently, the natural ability of the GSTs to interact with xenobiotic compounds was used for the development of simple and sensitive qualitative and quantitative assays. GSTs 
from different sources have been employed for detecting insecticides $[10,12,16,17]$. These assays were based on the inhibition of the GST-catalyzed reaction by xenobiotics, with detection achieved either spectrophotometrically or electrochemically.

In the present work we screened the inhibition sensitivity of a number of human GST (hGST) isoenzymes that belong to the alpha (hGSTA1-1), pi (allelic variants hGSTP1*A, hGSTP1*B, hGSTP1*C), theta (hGSTT2-2) and omega (hGSTO1-1) classes toward twentyseven different pesticides. We found that the isoenzyme hGSTA1-1 is more sensitive than the other isoenzymes toward the insecticides dieldrin and spiromesifen. Accordingly, hGSTA1-1 was used for the development and optimization of simple spectrophotometric kinetic assays for the determination of dieldrin and spiromesifen in water samples. Pesticides are included in a broad range of organic micro pollutants that have human health and ecological impacts. Different categories of pesticides have different types of effects on living organisms. Although terrestrial impacts by pesticides do occur, the principal pathway that causes ecological impacts is that of water contaminated by pesticide runoff. The interest in developing simple assays for the determination of pesticides in water samples has, therefore, been steadily increasing and considered essential for efficient environmental management and control $[10,14,15,17]$.

\section{Materials and methods}

\subsection{Materials}

Reduced glutathione (GSH), 1-chloro-2,4-dinitrobenzene (CDNB), bovine serum albumin (BSA), and ampicillin were obtained from Sigma-Aldrich Co (USA). Analytical standards of spiromesifen (99.9\%) and dieldrin (99.3\%) were obtained from Bayer CropScience AG (Leverkusen, Germany) and Sigma-Aldrich (St. Louis, USA), respectively. HPLC grade solvents, acetonitrile, acetone and methanol were purchased from Lab Scan (Dublin, Ireland). Ultrapure-grade HPLC water was obtained by purification of distilled water through a Milli-Q Gradient system (Millipore, Bedford, MA, USA). The pesticides: fenvalerate, permethrin, diazinon, malathion, carbaryl, atrazine, diuron, fluorodifen, alachlor, metolachlor, dichlorvos, omethoate, $\alpha$-cypermethrin, dieldrin, spirodiclofen, $\lambda$-cyhalothrin, spinosad, deltamethrin, aldrin, spiromesifen, thiacloprid, pirimicarb, methomyl, chlorpyriphos, endosulfan, carbofuran and fluazifop-p-butyl were purchased from Riedel de Haen (Germany). The expression plasmids pOXO4hGSTP1*B, pOXO4-hGSTP1*C pOXO4-hGSTA1-1 were gifts from Prof. C.S. Morrow (Department of Biochemistry, Wake Forest University School of Medicine, NC). The expression plasmids pQE30-hGSTO1-1 and pQE30-hGSTT2-2 were gifts from Prof. P. Board (John Curtin School of Medical Research, Australian National University, Australia).

\subsection{Methods}

\subsubsection{Subcloning of $h G S T P 1^{*} A$}

PCR was employed to amplify hGSTP1*A gene using the oligo primers synthesized to the $5^{\prime}$-region of the gene $\left(5^{\prime}-\right.$ ATGCCGCCCTACACCGTGGT- $3^{\prime}$ ) and to the $3^{\prime}$-end of the gene finishing at the TGA stop codon (5'-TCACTGTTTCCCGTTGCCAT$\left.3^{\prime}\right)$. The PCR reaction was carried out in a total volume of $50 \mu \mathrm{l}$ contained $1 \mu \mathrm{g}$ template cDNA, $0.125 \mathrm{mM}$ of each of the four deoxyribonucleotide triphosphates (dNTPs), $10 \mu \mathrm{l} 5 \times \mathrm{Pfu}$ buffer, 1 unit Phusion ${ }^{\circledR}$ High-fidelity DNA polymerase and $8 \mathrm{pmol}$ of each primer. The PCR procedure comprised 30 cycles of 2 min at $95^{\circ} \mathrm{C}, 2 \mathrm{~min}$ at $53^{\circ} \mathrm{C}$ and $2 \mathrm{~min}$ at $72^{\circ} \mathrm{C}$. A final extension time at $72^{\circ} \mathrm{C}$ for $10 \mathrm{~min}$ was performed after the 30th cycle.
The pEXP5-CT/TOPO ${ }^{\circledR} \mathrm{TA}$ kit was used for the direct insertion of PCR product into a T7 expression vector. The resulting expression construct pT7hGSTP1*A was sequenced along both strands and was used to transform competent BL21(DE3) Escherichia coli cells.

\subsubsection{Heterologous expression and purification of recombinant GSTs in E. coli}

BL21(DE3) E. coli cells harboring plasmids pT7hGSTP1*A, pOXO4-hGSTP1 ${ }^{*}$ B, pOXO4-hGSTP1 ${ }^{*}$ C, and pOXO4-hGSTA1-1 were grown in Luria-Bertani (LB) medium containing ampicillin $(100 \mu \mathrm{g} / \mathrm{mL}$ ) (for E. coli cells harboring the plasmid pT7hGSTP1*A) and chloramphenicol $(33 \mu \mathrm{g} / \mathrm{mL}$ ) (for E. coli cells harboring plasmids pOXO4-hGSTP1*B, pOXO4-hGSTP1 ${ }^{*} \mathrm{C}$, and pOXO4hGSTA1-1). The synthesis of GSTs was induced by addition of $1 \mathrm{mM}$ isopropyl- $\beta$-D-thiogalactopyranoside (IPTG) when the absorbance at $600 \mathrm{~nm}$ was 0.6. Four hours after induction, cells were harvested by centrifugation at $8000 \mathrm{rpm}$ and $4{ }^{\circ} \mathrm{C}$ for $20 \mathrm{~min}$, resuspended in phosphate buffer $(20 \mathrm{mM}, \mathrm{pH} 7)$, sonicated, and centrifuged at $13,000 \mathrm{rpm}$ for $5 \mathrm{~min}$. The supernatant was loaded to an epoxy-activated Sepharose CL-6B column coupled to glutathione (1,4-butanediol diglycidyl ether-GSH-Sepharose-CL6B, $1 \mathrm{~mL}$ ) [3], which was previously equilibrated with potassium phosphate buffer (20 mM, pH 7). Non-adsorbed protein was washed off with $10 \mathrm{~mL}$ equilibration buffer. Bound GST was eluted with equilibration buffer containing $10 \mathrm{mM}$ glutathione. Protein purity was $>95 \%$ as determined by $12 \%$ SDS-PAGE.

For the expression of GSTO1-1 and GSTT2-2, M15[pREP4] E. coli cells harboring plasmid pQE30hGST 01-1 and pQE30hGST T2-2 were grown in LB medium containing ampicillin $(100 \mu \mathrm{g} / \mathrm{mL})$ and kanamycin $(25 \mu \mathrm{g} / \mathrm{mL})$. Gene expression was induced by the addition of IPTG to a final concentration of $1 \mathrm{mM}$ when the absorbance at $600 \mathrm{~nm}$ had reached 0.6 . Four hours after induction the cells were harvested by centrifugation at $8000 \mathrm{rpm}$ for $20 \mathrm{~min}$ at $4{ }^{\circ} \mathrm{C}$, resuspended in potassium phosphate buffer $(50 \mathrm{mM}, \mathrm{pH} 8.0)$ containing sodium chloride $(0.3 \mathrm{M})$ and $10 \mathrm{mM}$ imidazole, sonicated, and finally centrifuged at $13,000 \mathrm{rpm}$ for $5 \mathrm{~min}$. The supernatant was loaded to a column of Ni-NTA-Sepharose ( $1 \mathrm{~mL}$, Sigma-Aldrich, USA), which was previously equilibrated with potassium phosphate buffer ( $50 \mathrm{mM}, \mathrm{pH} 8.0$ ) containing sodium chloride ( $3 \mathrm{M}$ ) and $10 \mathrm{mM}$ imidazole. Non-adsorbed protein was washed off with $10 \mathrm{~mL}$ equilibration buffer, followed by $10 \mathrm{~mL}$ of potassium phosphate buffer $(50 \mathrm{mM}, \mathrm{pH} 8)$, containing sodium chloride ( $3 \mathrm{M}$ ). Bound hGSTO1-1 and hGSTT2-2 were eluted with equilibration buffer containing different concentrations of imidazole $(20 \mathrm{mM}$, $100 \mathrm{mM}, 250 \mathrm{mM}$ ). Collected fractions ( $3 \mathrm{~mL}$ each) were assayed for GST activity. Protein purity was $>95 \%$ as determined by $12 \%$ SDS-PAGE.

\subsubsection{Protein determination}

Protein concentrations were determined according to the Bradford method [18] using BSA (fraction V) as standard.

\subsubsection{Assay of enzyme activity}

GST assays were performed by monitoring the formation of the conjugate of CDNB $(1 \mathrm{mM})$ with $\mathrm{GSH}(2.5 \mathrm{mM})$ at $340 \mathrm{~nm}$ $\left(\varepsilon=9.6 \mathrm{mM}^{-1} \mathrm{~cm}^{-1}\right)$ at $37^{\circ} \mathrm{C}$ according to a published method [19]. Observed reaction velocities were corrected for spontaneous reaction rates when necessary. All initial velocities were determined in duplicate in buffers equilibrated at constant temperature. Enzyme assays in the presence of pesticides were carried out in buffer containing 5-20\% (v/v) organic solvent (acetone) to increase solubility of pesticides. The solvent did not influence enzyme activity and integrity. According to definition, 1 unit of enzyme was taken as the amount of enzyme that gives $1.0 \mu$ mole of product per minute at $\mathrm{pH} 6.5$ and $37^{\circ} \mathrm{C}$. 
Pesticide screening and inhibition potency evaluation toward GSTs were carried out in the assay system described above in the presence of $100 \mu \mathrm{M}$ pesticide diluted in acetone. During the course of the assay (30-60 s) no measurable pesticide/GSH reaction was detected. The percentage enzyme inhibition was calculated using the following equation:

\%inhibition $=\frac{R_{0}-R_{i}}{R_{0}}$

where $R_{0}$ is the rate of absorbance increase for the uninhibited reaction and $R_{i}$ is the rate of increase for the inhibited reaction. Both $R_{i}$ and $R_{0}$ correspond to the same substrate concentration.

The $\mathrm{IC}_{50}$ values were determined in the assay system described above by measuring the GST activity in the presence of different concentrations of dieldrin $(0-0.08 \mathrm{mM})$ and spiromesifen $(0-0.09 \mathrm{mM})$ at $20^{\circ} \mathrm{C}, 25^{\circ} \mathrm{C}$ and $37^{\circ} \mathrm{C}$. The $\mathrm{IC}_{50}$ values were also determined in phosphate buffer of different $\mathrm{pH}$ ( $\mathrm{pH} \mathrm{6.5,} 7.0$ and 7.5) at $37^{\circ} \mathrm{C}$. The $\mathrm{IC}_{50}$ values were determined by fitting the concentration-response data to the following equation:

$\%$ inhibition $=\frac{100}{1+\left(\mathrm{IC}_{50} /[\mathrm{I}]\right)}$

where $[I]$ is the pesticide concentration. The $\mathrm{IC}_{50}$ values were determined using the program GraphPad Prism (GraphPad Software Inc., Version 5.03).

Waste treatment was carried out using granular activated carbon filter.

\subsubsection{Kinetic inhibition studies with dieldrin and spiromesifen}

Initial velocities for the hGSTA1-1-catalysed reaction with GSH as variable substrate were performed at $37^{\circ} \mathrm{C}$ in a total volume of $1 \mathrm{~mL}$ mixture containing $0.1 \mathrm{M}$ potassium phosphate buffer $(\mathrm{pH}$ 6.5), $1 \mathrm{mM} \mathrm{CDNB}$, and different concentrations of GSH in the range of $0.075-5.25 \mathrm{mM}$ in the absence or in the presence of different concentrations of dieldrin $(0-5 \mu \mathrm{M})$ or spiromesifen $(0-15 \mu \mathrm{M})$. With CDNB as a variable substrate, the reaction mixture (total volume $1 \mathrm{~mL}$ ) contained $0.1 \mathrm{M}$ potassium phosphate buffer ( $\mathrm{pH} 6.5$ ), $1 \mathrm{mM} \mathrm{GSH}$, and CDNB in the concentration range of $0.05-1.05 \mathrm{mM}$, in the absence or in the presence of different concentrations of dieldrin $(0-5 \mu \mathrm{M})$ or spiromesifen $(0-15 \mu \mathrm{M})$. The apparent kinetic parameters were determined using the computer program GraFit 3 (Erithacus Software Ltd., Version 3.06).

\subsubsection{Docking of dieldrin and spiromesifen into the hGSTA1-1 binding site.}

Molecular docking was carried out using Autodock Vina [20]. The structure of GSTA1-1 in complex with ethacrynic acid was used as the receptor (PDB code 1GSF) [21]. Default values were used during docking. The size of the docking grid was set to $40 \AA ̊ 40 \AA \times 40 \AA$ to encompass the $\mathrm{G}$ - and $\mathrm{H}$-site. The grid spacing was left at its default value $(0.375 \AA)$.

\subsubsection{Determination of the pesticides dieldrin and spiromesifen in natural water samples}

For pesticide determination, the rate of absorbance $(340 \mathrm{~nm}$ ) increase was recorded and the \% inhibition was calculated using Eq. (1). Pesticide recovery experiments were carried out using drinking water (collected from Athens water supply network) and mineral water samples (Korpi, NESTLE Hellas), spiked with known amounts $(0.8-10 \mu \mathrm{M})$ of dieldrin and spiromesifen.

\subsubsection{HPLC system and operating conditions}

Analytical standard stock solutions $(0.2 \mathrm{mg} / \mathrm{mL})$ of spiromesifen and dieldrin were made in methanol and acetone, respectively. Working standard solutions were obtained at various concentrations by dilution of the stock solution in methanol. These solutions were subsequently stored at $-20^{\circ} \mathrm{C}$. A standard stock solution containing both compounds at $100 \mu \mathrm{g} / \mathrm{mL}$ each, was prepared in methanol from the individual stock solutions. Six standard solutions of spiromesifen and dieldrin at concentrations from 0.1 to $10.0 \mu \mathrm{g} / \mathrm{mL}$ were prepared in methanol as calibration standards. Spiromesifen and dieldrin were determined by a Shimadzu HPLC system equipped with a binary solvent pump (LC-10ADvp), DGU14A degasser, CTO-10Avp column oven, SIL-10ADvp autosampler with volume injection set at $10 \mu \mathrm{L}$, and a UV diode array detector (SPD-M10Avp). Data acquisition and processing were performed with the LC/MS solution Ver. 3.0 Workstation. The

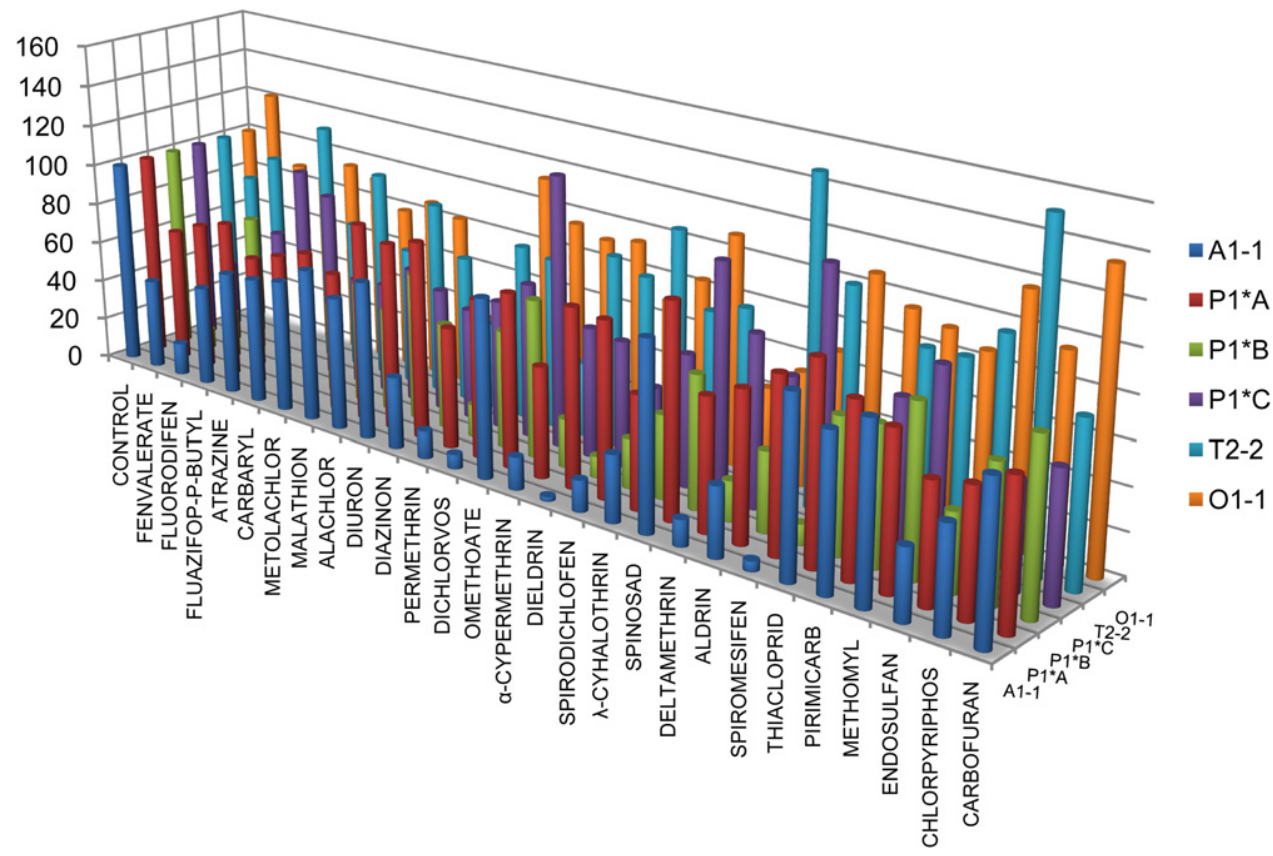

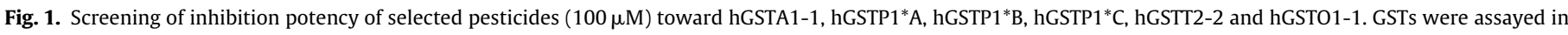
all measurements using CDNB-GSH assay system. 

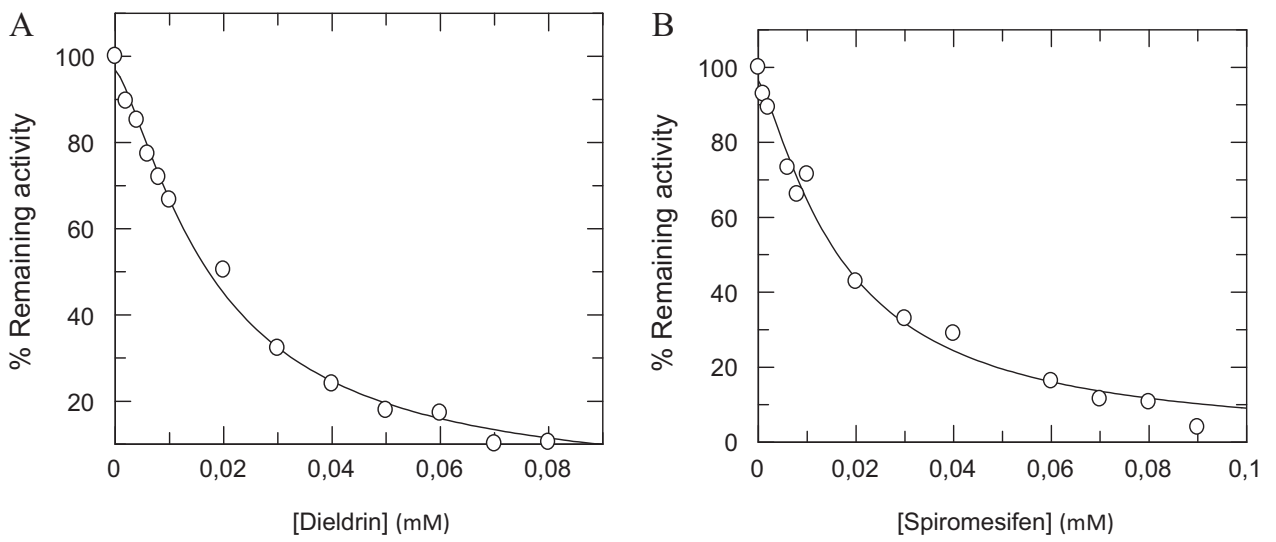

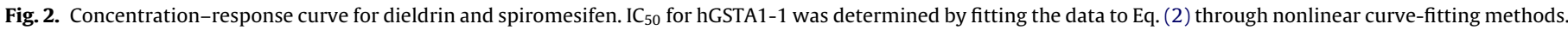
GSTs were assayed in all measurements using the CDNB-GSH assay system.

chromatographic separation was performed on a Discovery reversed-phase $C_{18}$ narrow-bore column $(250 \times 4.6 \mathrm{~mm}$ id, $5 \mu \mathrm{m}$ particle size), thermostatted at $40^{\circ} \mathrm{C}$. The mobile phase was acetonitrile- $0.1 \mathrm{M}$ acetic acid $(85: 15, \mathrm{v} / \mathrm{v})$, delivered isocratically at a flow-rate of $0.7 \mathrm{~mL} \mathrm{~min}^{-1}$ for $20 \mathrm{~min}$. The calibration plot was linear for the UV diode array detector over the range of $0.1-10 \mu \mathrm{g} / \mathrm{mL}$, and the detectable limit (LOD) of the analytical method was approximately $0.1 \mu \mathrm{g} / \mathrm{mL}$ for spiromesifen and $1 \mu \mathrm{g} / \mathrm{mL}$ for dieldrin. Linearity was determined by calibration curves at six concentrations ranged from 0.1 to $10.0 \mu \mathrm{g} / \mathrm{mL}$.
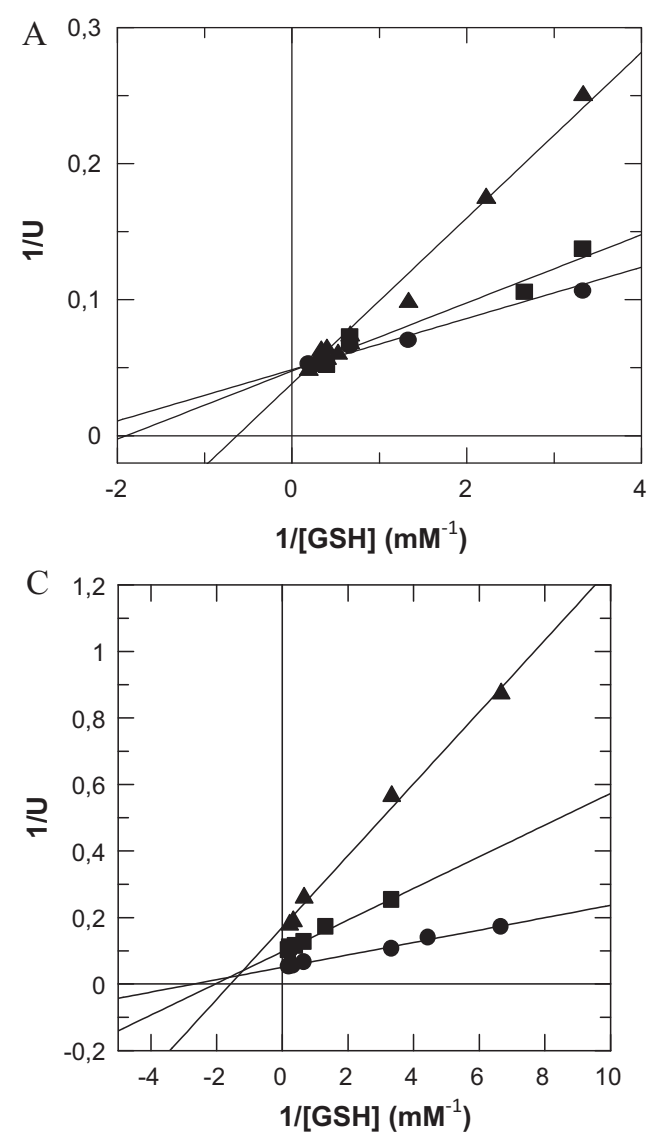

\section{Results and discussion}

\subsection{Screening the inhibition sensitivity of human GST isoenzymes by pesticides}

In the present work we screened the inhibition sensitivity of a number of human GST isoenzymes that belong to the alpha (hGSTA1-1), pi [allelic variants hGSTP1*A (I104/A113), hGSTP1*B (V104/A113) and hGSTP1*C (V104/V113)] [22], theta (hGSTT2-2) and omega (hGSTO1-1) classes toward a wide range
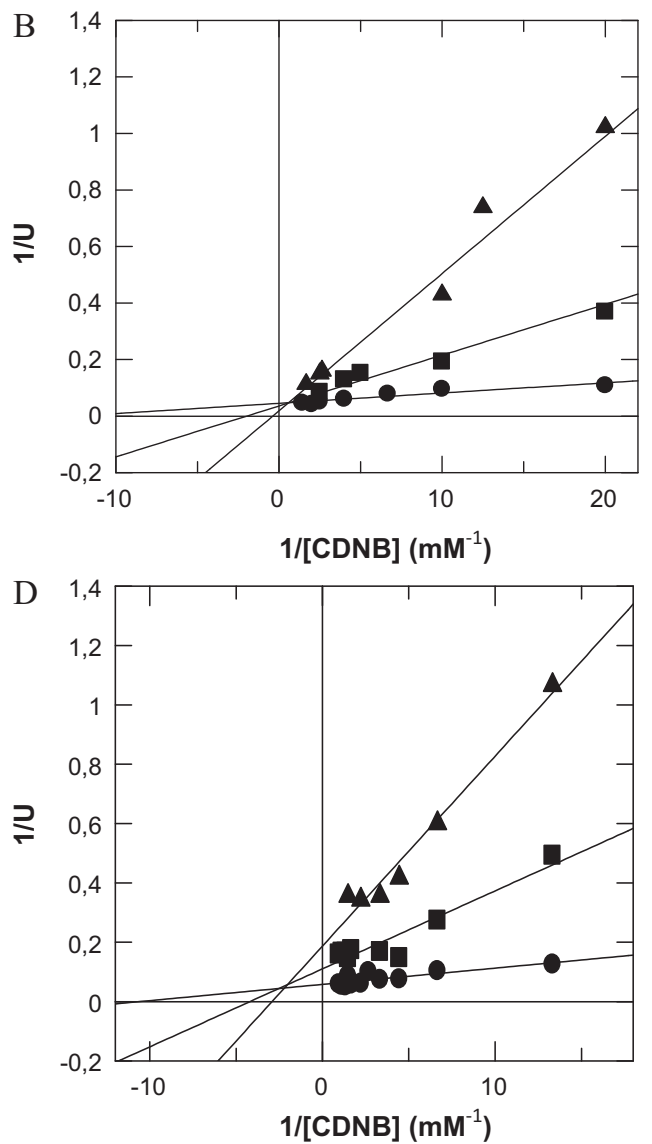

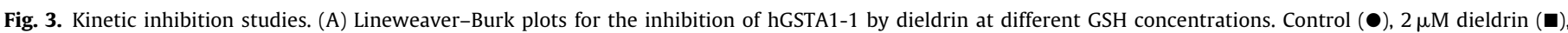

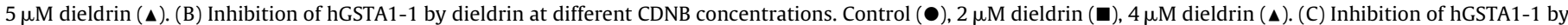

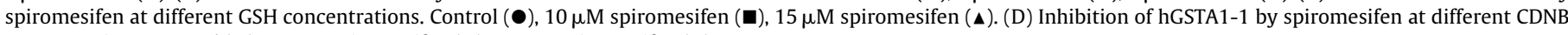

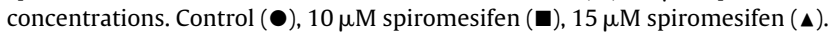


Table 1

$\mathrm{IC}_{50}$ values of dieldrin and spiromesifen for hGSTA1- 1 . IC 50 values were determined at pH 6.5 at different temperatures $\left(20^{\circ} \mathrm{C}, 25^{\circ} \mathrm{C}, 37^{\circ} \mathrm{C}\right)$, and at $37^{\circ} \mathrm{C}$ at different $\mathrm{pH}$ values ( $\mathrm{pH} 6.5,7.0,7.5)$.

\begin{tabular}{|c|c|c|c|}
\hline \multirow[t]{2}{*}{ Pesticides } & \multicolumn{3}{|c|}{$\mathrm{IC}_{50} \pm$ S.E.M at pH 6.5} \\
\hline & $37^{\circ} \mathrm{C}$ & $25^{\circ} \mathrm{C}$ & $20^{\circ} \mathrm{C}$ \\
\hline Dieldrin & $17.9 \pm 1.7 \mu \mathrm{M}$ & $34.5 \pm 4.5 \mu \mathrm{M}$ & $98.3 \pm 45.8 \mu \mathrm{M}$ \\
\hline Spiromesifen & $12.1 \pm 3.4 \mu \mathrm{M}$ & $79.5 \pm 9.7 \mu \mathrm{M}$ & $24.2 \pm 0.9 \mu \mathrm{M}$ \\
\hline \multirow[t]{2}{*}{ Pesticides } & \multicolumn{3}{|c|}{$\mathrm{IC}_{50} \pm$ S.E.M at $37^{\circ} \mathrm{C}$} \\
\hline & $\mathrm{pH}=6.5$ & $\mathrm{pH}=7.0$ & $\mathrm{pH}=7.5$ \\
\hline Dieldrin & $17.9 \pm 1.7 \mu \mathrm{M}$ & $47.2 \pm 3.3 \mu \mathrm{M}$ & $50.4 \pm 18.1 \mu \mathrm{M}$ \\
\hline Spiromesifen & $12.1 \pm 3.4 \mu \mathrm{M}$ & $62 \pm 12.9 \mu \mathrm{M}$ & $29.5 \pm 4.3 \mu \mathrm{M}$ \\
\hline
\end{tabular}

of pesticides. The best-suited enzyme to be used in analytical applications should be the most sensitive to xenobiotics to place the threshold of detection as low as possible [10]. Initial screening was, therefore, performed to evaluate whether the selected pesticides may act as inhibitors against the selected GST isoenzymes.

The inhibition potency of a wide range of pesticides, including insecticides, fungicides and herbicides (Fig. 1) were evaluated at $100 \mu \mathrm{M}$ concentration for their ability to inhibit GST activity of the selected human isoenzymes. All pesticides showed time-independent inhibition, indicating that the inhibitors bind reversibly to the enzymes. From the results presented in Fig. 1 it is evident that bulky compounds with two aromatic rings (e.g. phenylurea-based insecticides such as fenvalerate, fluorodifen, permethrin, $\alpha$-cypermethrin, $\lambda$-cyhalothrin) acted as strong inhibitors showing approximately $>60 \%$ inhibition. On the other hand, aliphatic insecticides such as malathion showed in general lower inhibition potency. Similarly, pesticides with one aromatic ring (e.g. diuron, diazinon, atrazine, and alachlor) exhibited low inhibition potency. It is noteworthy that some pesticides (e.g. endosulfan, carbofuran, and fenvalerate) promoted activation of hGSTO1-1. This phenomenon has already been observed with other GSTs [23].

In general, hGSTA1-1 is more susceptible to inhibition by pesticides compared to the other isoenzymes, whereas hGSTO1-1 was the less. Thus, hGSTA1-1 was selected for further study. The insecticides dieldrin and spiromesifen exhibited the highest inhibition potency resulting in a decrease of hGSTA1-1 activity by $>95 \%$ (Fig. 1). The $\mathrm{IC}_{50}$ values of dieldrin and spiromesifen at $37^{\circ} \mathrm{C}$ and pH 6.5 (Fig. 2) were $17.9 \pm 1.7 \mu \mathrm{M}$ and $12.1 \pm 3.4 \mu \mathrm{M}$, respectively.

\subsection{Effect of $p H$ and temperature on hGSTA1-1 inhibition by dieldrin and spiromesifen}

To evaluate the effect of temperature and $\mathrm{pH}$ on the inhibition of dieldrin and spiromesifen toward hGSTA1-1, the IC $_{50}$ values were determined at different $\mathrm{pH}$ and temperature conditions (Table 1). The results showed that $\mathrm{IC}_{50}$ values are both temperature- and $\mathrm{pH}-$ dependent, suggesting that changes in temperature and $\mathrm{pH}$ affect significantly the affinity of the pesticides for the enzyme. In particular, the inhibition potency of dieldrin and spiromesifen decreased considerably with increases in $\mathrm{pH}$ and decreases in temperature. The $\mathrm{IC}_{50}$ values reached their minimum at $37^{\circ} \mathrm{C}$ and $\mathrm{pH} 6.5$ for dieldrin and spiromesifen. Based on the structure of dieldrin and spiromesifen, it is evident that a "mixed" type (hydrophobic as well as hydrophilic) interaction may contribute to the protein-ligand complex formation (see also next paragraph) and thus the "mixed" type interaction is expected to be both $\mathrm{pH}$ and temperature sensitive, in agreement with the results presented in Table 1.

\subsection{Delineation of the hGSTA1-1 pesticide binding site by kinetic inhibition and molecular modeling studies}

Kinetic inhibition studies were carried out to localize the dieldrin and spiromesifen binding site on hGSTA1-1. The inhibition patterns are illustrated in Fig. 3. Dieldrin exhibited a mixed-type of inhibition with respect to GSH $\left(K_{i}=2.3 \pm 0.1 \mu \mathrm{M}\right)$ and CDNB $\left(K_{i}=0.1 \pm 0.01 \mu \mathrm{M}\right)$. In the obtained Lineweaver-Burk plot, the lines for the uninhibited enzyme and for the two different concentrations of dieldrin intersected to the left of the $1 / v$ axis and above the $1 /[S]$ axis. Spiromesifen exhibited the same (mixed-type) inhibition pattern toward GSH $\left(K_{i}=2.2 \pm 0.12 \mu \mathrm{M}\right)$ and $\operatorname{CDNB}\left(K_{i}=0.4 \pm 0.02 \mu \mathrm{M}\right)$. The mixed-type inhibition observed indicates that dieldrin and spiromesifen bind to both free-enzyme and enzyme-substrate complex, but their affinities for these two forms of the enzyme are different $\left(K_{i} \neq K_{i^{\prime}}\right)$. Thus, dieldrin and spiromesifen interfere with substrate binding (i.e. they increase $K_{m}$ ) and hamper catalysis in the enzyme-substrate complex (i.e. they decrease $V_{\text {max }}$ ).

The isoenzyme hGSTA1-1 exhibits wide ligand-binding specificities since the size, shape and high flexibility of the H-site make it suitable for accommodating a wide variety of large hydrophobic ligands $[7,8]$. Neither dieldrin nor spiromesifen bears any strong structural resemblance to the substrates/inhibitors found in the crystal structures of the enzyme available in PDB (Fig. 4A). Thus, molecular docking studies were employed to provide a detailed picture of dieldrin and spiromesifen interactions with hGSTA1-1. The most favorable binding mode of dieldrin and spiromesifen with hGSTA1-1 is shown in Fig. 4B. Both compounds bind to the enzyme at distinct positions that partially overlap both the G- and H-site, very close to the ethacrynic acid binding site as observed in the X-ray structure (PDB code 1GSF; [21]). Analysis of the putative binding site of each inhibitor suggests that the binding of dieldrin and spiromesifen to the enzyme may be primarily achieved by hydrophobic interactions (Fig. 4C) with the contribution of some polar interactions (H-bonds) that provide the driving force for positioning and recognition of these compounds. In the case of dieldrin, the hexachloro-ring is exposed toward the solvent whereas the epoxy part of the molecule interacts with the protein. The bulk of the interactions with the enzyme involve residues from the C-terminal helix (Ala216, Phe220, Phe222). In addition, a hydrogen bond may be formed with the hydroxyl group of the catalytic residue Tyr9.

The predicted mode of interaction of the spiromesifen with hGSTA1-1 is shown in Fig. 4B. The molecule packs such that it forms van der Waals contacts with Phe220 and Phe222. The epoxy ring of spiromesifen is favorably positioned to form three hydrogen bonds with $\operatorname{Arg} 14$. An additional hydrogen bond is formed between the carbonyl group and the Tyr9 side chain hydroxyl group. The aromatic ring is able to form $\pi$-aromatic interaction with Phe220 and the trimethyl group is situated in a hydrophobic pocket close to Met208, Ala12 and Phe10. Superposition (Fig. 4D) of the binding modes of the two ligands with the GSH-ethacrynic acid conjugate (1GSE structure) showed that dieldrin and spiromesifen overlap with both the GSH (G-site) and ethacrynic acid (H-site) moieties. The available molecular surface areas of $\mathrm{G}$ - and $\mathrm{H}$-site are large enough $\left(\sim 1200 \mathrm{~A}^{2}\right)$ to allow simultaneously the accommodation of both the reactant and the pesticide, suggesting that the mixed-type inhibition observed by kinetic analysis (Fig. 3) is a reasonable model.

Besides the binding mode described above, an alternative docking result was obtained in which dieldrin and spiromesifen bind in a different location, formed between $\mathrm{H} 4, \mathrm{H} 5$ and $\mathrm{H} 6$ helices (Fig. 4E). This site is positioned next to the H-site, consistent with the model of mixed-type inhibition. However, the long 

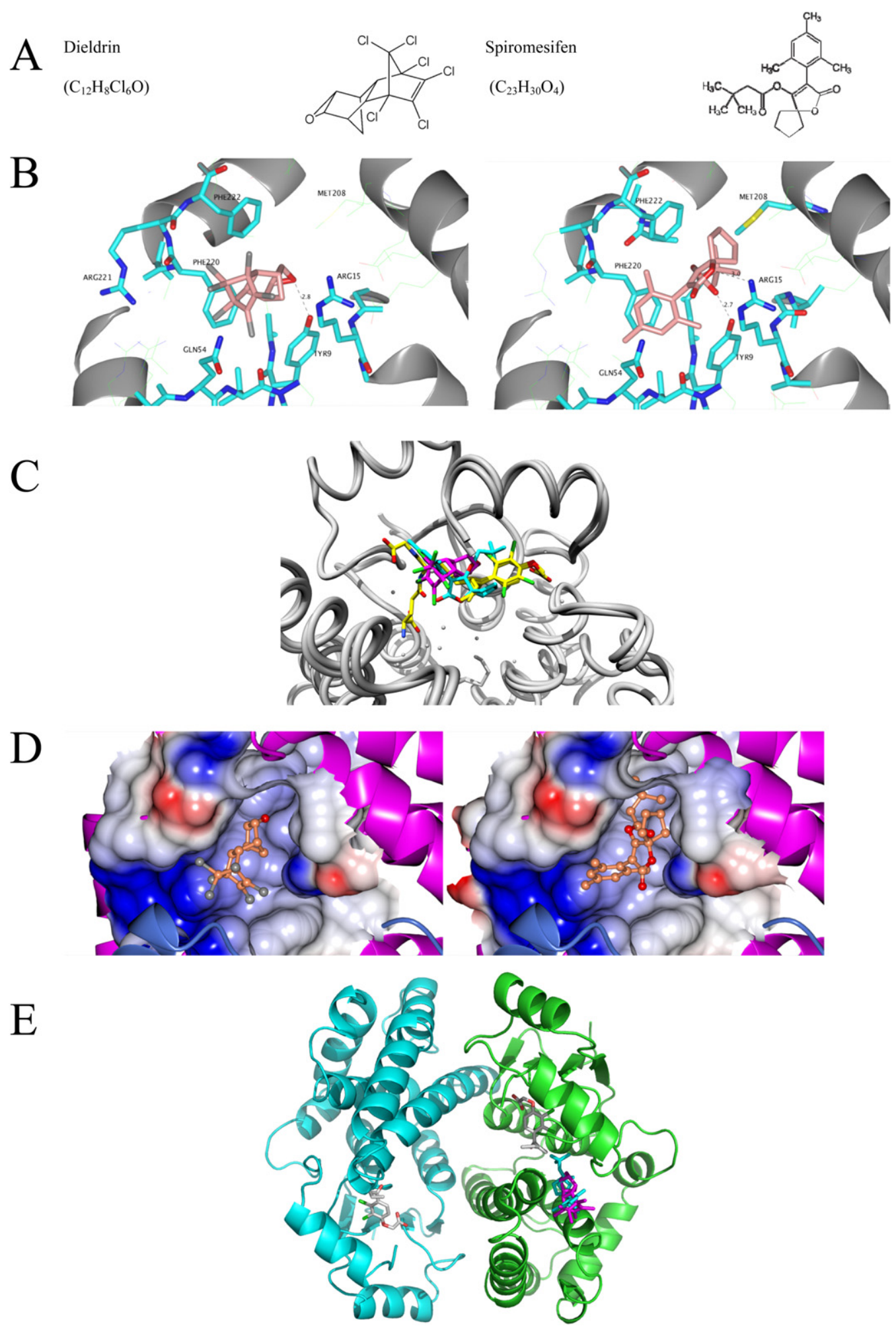

Fig. 4. (A) The structures of dieldrin (left) and spiromesifen (right). (B) The predicted mode of interaction of hGSTA1-1 with dieldrin (left) and spiromesifen (right). Side chains of residues contacting the ligand are shown as sticks and labeled. (C) Superposition of dieldrin (magenta) and spiromesifen (turquoise) with the GSH-ethacrynic acid conjugate (yellow, PDB code 1GSE; [21]). (D) Electrostatic potential (in $k T / e$ ) surface around dieldrin (left) and spiromesifen (right). Red, blue and white denote negative $(-0.5)$, positive $(+0.5)$ and neutral $(0.0)$ charges, respectively. Figures were drawn with QtMG 2.5 [28]. (E) Representation of the alternative binding site. The figure shows dieldrin (magenta) and spiromesifen (turquoise) bound to the less favorable binding site and ethacrynic acid bound at the H-site (PDB code 1GSF). (For interpretation of the references to color in this figure legend, the reader is referred to the web version of the article.) 

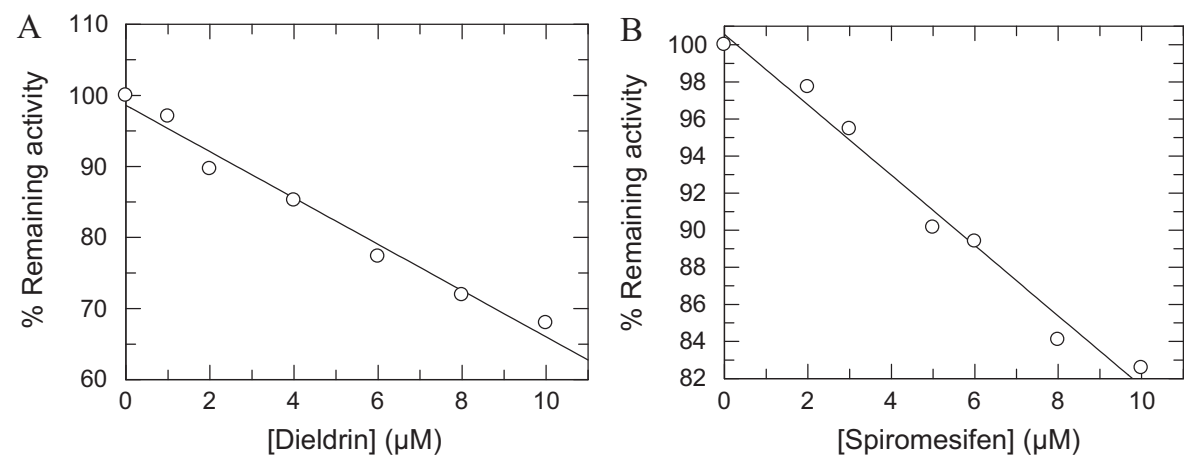

Fig. 5. Calibration graphs for dieldrin (A) and spiromesifen (B) using hGSTA1-1. Each point represents the average of three determinations.

distance from the active site and the absence of direct structural communication between these two sites exclude the possibility that the second binding site represents a reasonable allosteric site. Moreover, the free energy score is less favorable and the binding mode appears less satisfactory since the apolar rings are exposed toward the (polar) solvent without showing any hydrogen bonds. Accordingly, the binding mode discussed above (Fig. 4B) should be preferred.

\subsection{The basis of a spectrophotometric kinetic assay for the} determination of dieldrin and spiromesifen in water

hGSTA1-1 was used for the development of a simple photometric assay that explores the ability of dieldrin and spiromesifen to act as strong inhibitors toward this enzyme. The sensing scheme, in the proposed assay, is based on the ability of GST to catalyze the conjugation of GSH with CDNB, resulting in a GSH-CDNB conjugate which adsorbs at $340 \mathrm{~nm}$. The concentration of dieldrin or spiromesifen may be determined indirectly by measuring the different degree of product formation due to enzyme inhibition by dieldrin or spiromesifen. The enzyme activity change in the presence of dieldrin and spiromesifen can be related to the amounts of these compounds in the assay using calibration curves.

Fig. 5A and B shows the calibration curves obtained for dieldrin and spiromesifen dissolved in distilled water. It can be seen that the percent of enzyme inhibition can be linearly related to dieldrin and spiromesifen concentration in bulk solution within the concentration range of $0-10 \mu \mathrm{M}$, by the following equations:

For dieldrin : $y=-3.26 x+98.6\left(R^{2}=-0.990\right)$

For spiromesifen : $y=-1.89 x+100.6\left(R^{2}=-0.998\right)$

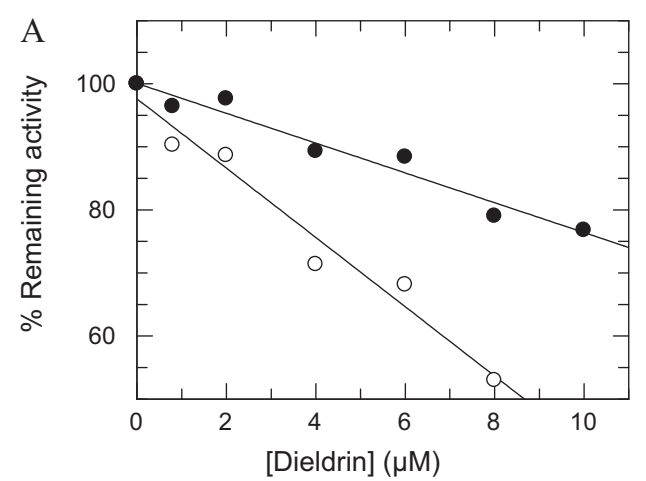

The reproducibility of the assay response, expressed as relative standard deviation (RSD), was in the order of $1.9 \%(N=10)$. Dieldrin recoveries ranged between 99.7 and $102 \%$, with an average value of $101 \pm 2.5 \%(N=5)$. Spiromesifen recoveries ranged between 95.3 and $101.3 \%$, with an average value of $99.7 \pm 2.5 \%(N=5)$.

\subsection{Determination of pesticides in real water samples}

The present method was further evaluated using finished drinking water and bottled mineral water samples. Fig. $6 \mathrm{~A}$ and $\mathrm{B}$ shows the calibration curves obtained for dieldrin and spiromesifen using finished drinking water and bottled mineral water. It can be seen that the percent of enzyme inhibition shows different response when the pesticides were dissolved in real water samples compared to distilled water (Fig. 5). This may be due to the different salt and organic content in the two water samples. The percent of enzyme inhibition shows linear response toward dieldrin and spiromesifen concentration within the concentration range of $0-10 \mu \mathrm{M}$. The linearity is described by the following equations.

For dieldrin:

$y=-5.49 x+97.6\left(R^{2}=-0.98\right)$ for drinking water and $y=-2.36 x+100.05\left(R^{2}=-0.98\right)$ for mineral water.

For spiromesifen:

$y=-3.98 x+99.03\left(R^{2}=-0.98\right)$ for drinking water and $y=-2.69 x+99.26\left(R^{2}=-0.98\right)$ for mineral water.

The application of the present method for the determination of dieldrin and spiromesifen was also investigated by recovery experiments using finished drinking water and bottled mineral water samples spiked with a known amount of dieldrin and spiromesifen. Table 2 shows the results of the recovery experiments.

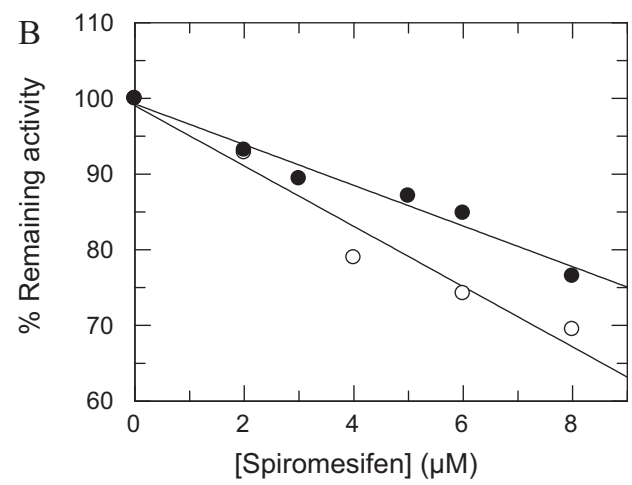

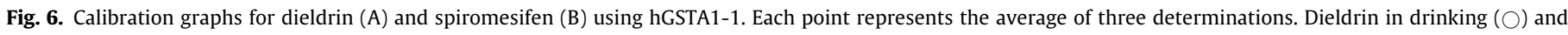
mineral $(\bullet)$ water samples. Spiromesifen in drinking $(\bigcirc)$ and mineral $(\bullet)$ water samples. 

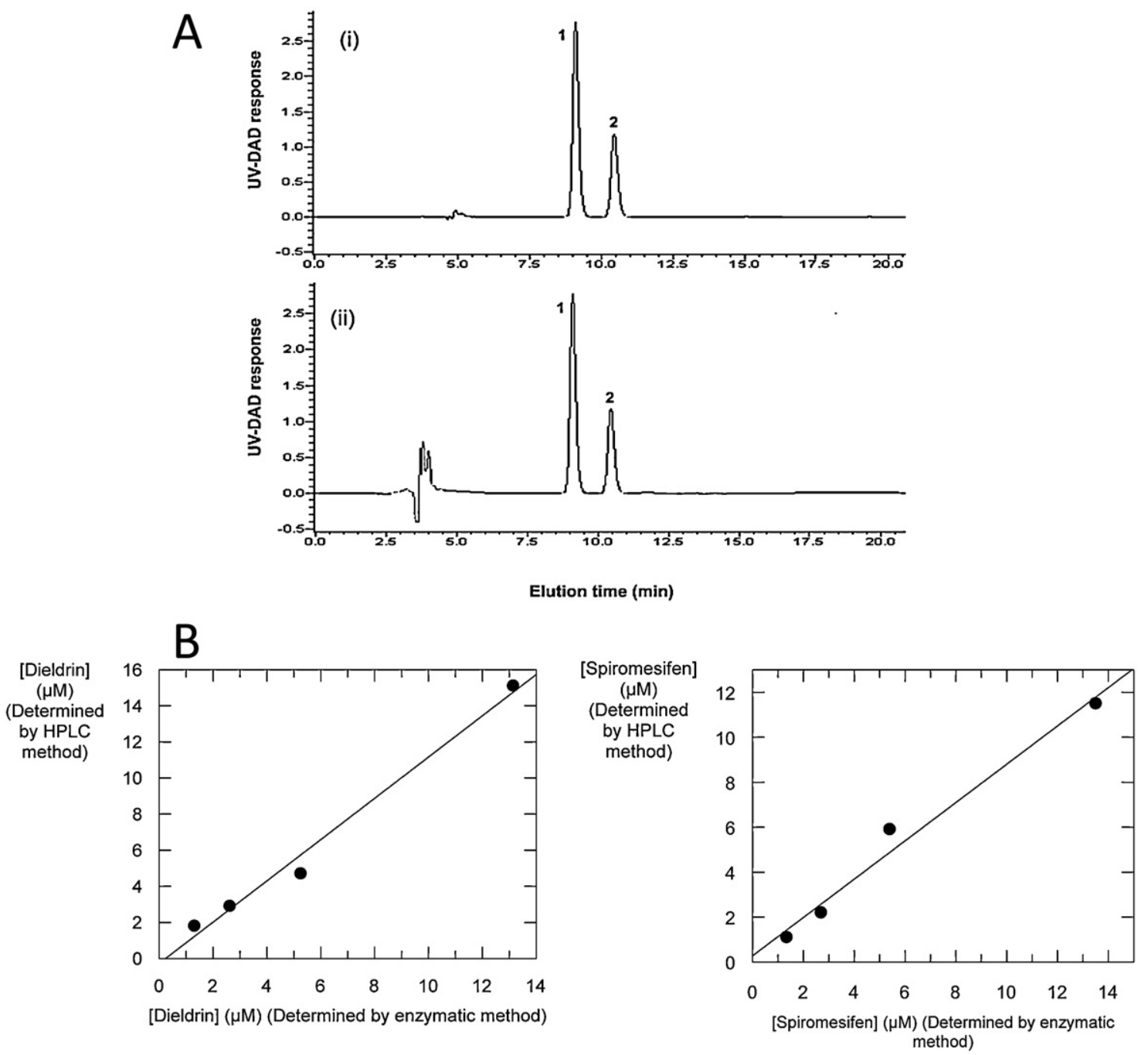

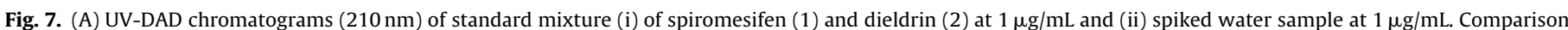

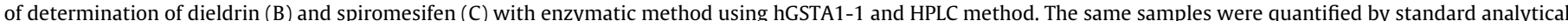
HPLC method and by the hGSTA1-1 enzymatic assay proposed in the present study.

Dieldrin recoveries in drinking water samples ranged between 91 and $110 \%$ with an average value of $102 \pm 8 \%$ and between 94 and $96 \%$ with an average value of $94.5 \pm 1.1 \%$, for spiromesifen. Dieldrin recoveries in mineral water ranged between 93 and 104\% with an average value of $99.3 \pm 4.4 \%$ and between 97 and $100 \%$ with an average value of $98.8 \pm 1.7 \%$ for spiromesifen. These values are in agreement with the acceptable recovery range for drinking water [24]. Drinking water samples gave the lowest recovery for

Table 2

Pesticide recovery experiments in water samples spiked with known amounts of each pesticide.

\begin{tabular}{|c|c|c|c|c|}
\hline \multirow[t]{2}{*}{ Sample } & \multicolumn{2}{|l|}{ Dieldrin } & \multicolumn{2}{|l|}{ Spiromesifen } \\
\hline & Added $(\mu \mathrm{M})$ & Recovery (\%) & Added $(\mu \mathrm{M})$ & Recovery (\%) \\
\hline \multirow{4}{*}{$\begin{array}{l}\text { Finished } \\
\text { drinking } \\
\text { water }\end{array}$} & 0.8 & 110 & 2 & 94 \\
\hline & 2 & 102 & 4 & 96 \\
\hline & 4 & 91 & 6 & 94 \\
\hline & 6 & 105 & 8 & 94 \\
\hline \multirow{5}{*}{$\begin{array}{l}\text { Mineral } \\
\text { water }\end{array}$} & 0.8 & 97 & 0.8 & 100 \\
\hline & 2 & 100 & 2 & 97 \\
\hline & 6 & 104 & 3 & 97 \\
\hline & 8 & 103 & 6 & 100 \\
\hline & 10 & 93 & 10 & 100 \\
\hline
\end{tabular}

spiromesifen values among the samples tested, probably due to the high ion concentration of these samples.

\subsection{Comparison of determination of dieldrin and spiromesifen with hGSTA1-1 and HPLC method}

Dieldrin and spiromesifen were quantified by hGSTA1-1 assay developed in this study. The results were compared with those obtained from standard HPLC methodology. Dieldrin and spiromesifen quantities were calculated using standard curves that were prepared from known concentrations of standards for the HPLC-UV-DAD analysis (Fig. 7A). Fig. 7B and C depict the correlation between the analysis of samples by hGSTA1-1 assay and HPLC-UV-DAD. Quantification showed linearity with a correlation coefficient of $R^{2}=0.98$ for dieldrin and spiromesifen, indicating that the proposed hGSTA1-1 assay provides comparable results with the standard HPLC method for quantification of dieldrin and spiromesifen with satisfactory accuracy.

The simple assay described above offers clear and distinct advantages, such as low cost, real-time detection with minimum sample preparation and sample handling, over standard analytical methods for the direct monitoring of dieldrin and spiromesifen. The application of GST inhibition test provides a new method 
for quantification of dieldrin and spiromesifen with satisfactory reproducibility and accuracy. The employed GST enzyme system is generally well characterized, stable, and easily reproducible using recombinant DNA technology [25]. The enzyme can be expressed in E. coli at high level and purified in a high yield (approx. $10-20 \mathrm{mg}$ protein/L culture). This amount is sufficient for more than $2.4 \times 10^{5}$ assays. The enzyme-based assays have potential advantages over bioassays and other analytical methods based on HPLC and GC/MS $[26,27]$ in terms of lower cost and technical complexity. Moreover, they provide reasonable sensitivity for certain applications, such as the direct determination of pesticide residues in water samples.

\section{Acknowledgments}

The authors thank the Ministry of Education, Lifelong Learning, and Religious Affairs for the financial assistance provided. This work was performed within the program HERACLITUS II, co-funded by the European Union - European Social Fund \& National Resources.

\section{References}

[1] E.G. Chronopoulou, N.E. Labrou, Recent Pat. Biotechnol. 3 (2009) 211-223.

[2] J.D. Hayes, J.U. Flanagan, I.R. Jowsey, Annu. Rev. Pharmacol. Toxicol. 45 (2005) 51-88.

[3] I. Axarli, P. Dhavala, A.C. Papageorgiou, N.E. Labrou, J. Mol. Biol. 385 (2009) 984-1002.

[4] R.N. Armstrong, Chem. Res. Toxicol. 10 (1997) 2-18.

[5] B. Mannervik, U.H. Danielson, CRC Crit. Rev. Biochem. 23 (1988) 283-337.
[6] A.J. Oakley, Curr. Opin. Struct. Biol. 15 (2005) 716-723.

[7] Y. Sayed, J.A. Hornby, M. Lopez, H. Dirr, Biochemistry 363 (2002) 341-346.

[8] D. Kolobe, Y. Sayed, H.W. Dirr, Biochem. J. 382 (2004) 703-709.

[9] I.A. Axarli, D.J. Rigden, N.E. Labrou, Biochem. J. 382 (2004) 885-893.

[10] P. Kapoli, A. Axarli, D. Platis, M. Fragoulaki, M. Paine, J. Hemingway, J. Vontas, N.E. Labrou, Biosens. Bioelectron. 24 (2008) 498-503.

[11] S. Mukanganyama, M. Bezabih, M. Robert, B.T. Ngadjui, G.F. Kapche, F. Ngandeu, B. Abegaz, J. Enzyme Inhib. Med. Chem. 26 (2011) 460-467.

[12] A.A. Enayati, J.G. Vontas, G.J. Small, L. McCarroll, J. Hemingway, Med. Vet. Entomol. 15 (2001) 58-63.

[13] A. Amine, H. Mohammadi, I. Bourais, G. Palleschi, Biosens. Bioelectron. 21 (2006) 1405-1423.

[14] M. Pohanka, K. Musilek, K. Kuca, Curr. Med. Chem. 16 (2009) 1790-1798.

[15] Y. Miao, N. He, J.J. Zhu, Chem. Rev. 110 (2010) 5216-5234.

[16] A.A. Enayati, C. Lengeler, T. Erlanger, J. Hemingway, Trans. R. Soc. Trop. Med. Hyg. 99 (2005) 369-378.

[17] E. Morou, H.M. Ismail, A.J. Dowd, J. Hemingway, N. Labrou, M. Paine, J. Vontas, Anal. Biochem. 378 (2008) 60-64.

[18] M.M. Bradford, Anal. Biochem. 72 (1976) 248-254.

[19] N.E. Labrou, L.V. Mello, Y.D. Clonis, Biochem. J. 358 (2001) 101-110.

[20] O. Trott, A.J. Olson, J. Comput. Chem. 31 (2010) 455-461.

[21] A.D. Cameron, I. Sinning, G. L'Hermite, B. Olin, P.G. Board, B. Mannervik, T.A. Jones, Structure 3 (1995) 717-727.

[22] F. Ali-Osman, O. Akande, G. Antoun, J.X. Mao, J. Buolamwini, J. Biol. Chem. 272 (1997) 10004-10012.

[23] D.P. Dixon, R. Edwards, J. Biol. Chem. 285 (2010) 36322-36329.

[24] P. Cunniff, Official Methods of Analysis: Pesticide and Industrial Chemical Residues, 16th ed., AOAC International Press, 1999.

[25] J. Wang, W. Chow, D. Leung, Anal. Bioanal. Chem. 396 (2010) 1513-1538.

[26] K. Banerjee, J. AOAC Int. 93 (2010) 353-354.

[27] E. Chronopoulou, I. Axarli, I. Nianiou-Obeidat, P. Madesis, A. Tsaftaris, N. Labrou, Curr. Chem. Biol. 5 (2011) 64-74.

[28] L. Potterton, S. McNicholas, E. Krissinel, J. Gruber, K. Cowtan, P. Emsley, G.N. Murshudov, S. Cohen, A. Perrakis, M. Noble, Acta Crystallogr. D Biol. Crystallogr. 60 (2004) 2288-2294. 